\title{
Information society skills: Is knowledge accessible for all? Part II
}

\author{
David Fonseca $^{1} \cdot$ Miguel Ángel Conde ${ }^{2}$
}

Published online: 7 July 2017

(C) Springer-Verlag GmbH Germany 2017

\section{Introduction}

The emergence and popularization of the Information and Communications Technologies (ICTs) changes the current educational landscape [1]. In the teaching and learning processes, technology is increasingly present every day. ICTs facilitate individuals to learn anywhere and at any time [2]. In fact, by using ICT, access to knowledge acquisition is not restricted to formal contexts such as the educational institutions. People can also acquire skills during their daily life [3], in an intentional and structured way (known as non-formal learning [4]) or in informal contexts [5], such as talking with friends, playing games, using their mobile devices, looking for information in the Internet (what is known as informal learning). This means that students are acquiring skills continuously, and in many cases, they are unaware of doing so [6]. Considering all this options, there is a necessity to explore how skills are acquired and/or validated in each context.

Beyond these formal, non-formal and informal contexts of learning, it is necessary to explore how people acquire their skills. In this sense, not all people learn in the same way; there is lot of research work dealing with the idea of digital natives and digital immigrants [7-9]. Taking into account these groups, we can affirm that not all digital

David Fonseca

fonsi@salle.url.edu

Miguel Ángel Conde

miguel.conde@unileon.es

1 La Salle, Ramon Llull University, Quatre Camins 2, 08022 Barcelona, Spain

2 Universidad de León, Campus de Vegazana s/n, 24071 León, Spain natives or immigrants' improve their skills in the same way, and there are other specific collectives that should not be forgotten, such as older people and people with disabilities [10-12]. For these groups, as well as for disadvantaged environments or societies where the technology and new devices do not have a strong presence, the use of ICT can be something exclusive. Therefore, the need arises to facilitate knowledge and skills acquisition for all.

The study of how to improve universal access to digital information and how to improve society skills to achieve this general objective is the starting point of the present special issue. In this context, it is necessary to analyze where and when learning happens, how it happens, and what are the needs, aims and abilities of the learners. In order to do so, it is necessary to explore existing methodologies, frameworks and tools used to access and manage knowledge, and whether they make it accessible for all. Digital content, services, systems and methodologies have been studied over the last several decades to improve and generate new models and methods for accessing content (especially rules and recommendations for disabled users [13]). These efforts are dynamic, particularly considering the constant technological revolution that continuously transforms these devices and their capabilities. This special issue focuses on research work related to the design, development, use of systems, content and all types of knowledge management as well as mixed evaluation [14].

The UAIS special issue comes after the successful organization of two international events:

- The invited session entitled "Knowledge Society for all. New trends in Education," organized in the context of the 18th HCI International Conference 2016, in Toronto, Canada (http://2016.hci.international), thematic area "Learning and Collaboration Technologies," with 21 
papers accepted, and the Best Paper Award of the thematic area [15].

- The invited session entitled "Open and Social Environments for e-Learning and Educational Assessment," organized in the context of the 17th HCI International Conference 2016, in Los Angeles (California), USA (http://2015.hci.international/), thematic area "Learning and Collaboration Technologies," with 13 papers accepted.

The development of this special issue involves three stages. The first consisted of the reception and evaluation of abstracts, as a way to reject those works out of the scope of the special issue. We received 31 abstracts to be evaluated, and 23 were selected. In the second stage, these papers were evaluated through a peer review process. Each paper was reviewed by three experts on the special issues topics. The papers were distributed and assigned according to the expertise and field of study of the different reviewers.

During the third stage, feedback was provided to the authors that had to correct their manuscripts and resubmit them. Once the review was completed, authors were contacted regarding the acceptance or rejection of their papers. A total of 16 papers were accepted after these three stages.

In this second part, we present eight papers describing studies, models and methodologies, systems and experiences, and evaluations related to different approaches in the field of information society skills and the accessibility of the contents and knowledge.

To start, Tihomir Orehovački and Snježana Babić [16] proposed a quality model that captures the particularities of social Web applications when used on mobile devices. Following a literature review of the framework, they identify a set of variables in order to design a conceptual model in the form of a mobile quality requirements tree. They have carried out an empirical study to assess the reliability of the model with the main conclusion that it is necessary to pay attention to measuring relevant dimensions of system quality followed by assessing elements of service quality, user experience, performance and effort. They found that attributes such as recoverability, loyalty, reliability, response time, customizability contribute to the overall perceived mobile quality of social Web applications designed for collaborative writing.

The work by Fidalgo-Blanco et al. [17] proposed the integration of the classic flip teaching model with a knowledge spiral that involves ontological and time dimensions. The flip teaching model usually involves students/trainees attending lectures outside of class time, which normally is dedicated to practical exercises. The authors assume the role of the student as a person who is able to share the knowledge previously acquired on a subject in order to improve the learning process of peers. For their propose, they carried out a quasi-experimental method to prove that the new model, called ontological flip teaching, increases the effectiveness and efficiency of the classical flip teaching model in the acquisition of the teamwork competence.

Ferrándiz et al. [18], in their paper, analyze the implementation of a building information modeling (BIM) approach in a construction course. Nowadays, the digital implementation of construction content in the Architectural Engineering at United Arab Emirates University is realized using AutoCAD. With this new approach, the authors seek to evaluate the improvement in students' motivation, performance and satisfaction using a quasi-experimental design. The results show that BIM solutions improve the student work efficiently and the understanding of the course material, which lead them to improve their motivation and satisfaction using Revit (the BIM solution selected in order to maintain an affordable connection with the previous software used, AutoCAD). Due to these results, the construction course has been redesigned in order to adapt the content explanation to the BIM solutions.

With regard to the migration process of Information Technologies (IT) to the cloud computing framework, Cardoso et al. [19] had investigated how an IT Infrastructure Library (ITIL) could be useful to the migration of services, applications, and data to cloud computing. Moreover, they present a discussion about how these processes help people improve their skills in knowledge accessibility. The research was validated with the implementation of a case study and with interviews with stakeholders of the whole process. The results show how ITIL provides a common language between the customer and the cloud service providers, improving support in the decisionmaking process and reducing its learning process, a clear result of the improvement in the system's access to data.

Following in the IT framework, Krizanovic [20] analyzed how to reduce the digital divide in the use of broadband solutions in rural areas. To define new strategies for the deployment and adoption of rural broadband solutions, the authors proposed, in a first stage, an extended techno-economic assessment process. The results of the analyses are used in a second stage for a new standard techno-economic modeling process, which is finally demonstrated for a case study in a rural scenario. It is clear that the fact that broadband access is not available in the majority of rural areas worldwide creates a digital divide between the humans and their place of living. The proposal is a starting point for improving universal access to digital information and improving the digital skills of the rural population. The results could be useful to both network operators and broadband market regulators when choosing the best deployment solutions and broadband deployment strategies. 
Pileggi [21] in his paper discussed the changes and the innovation that Google Scholar (GS) has introduced as a tool which provides a simple way to broadly search for scholarly literature across many disciplines and sources. Compared to other non-free tools, GS also provides citation metrics and is open to a much larger audience according to its open data philosophy. On the other hand, Pileggi proposes possible improvements for analysis on academic citations. These new approaches are aimed at considering a GS profile providing a social perspective on academic citations. By adopting the contextual processing and analysis proposed in this paper, the typical advice looking at common metrics could be replaced by objective, effectively comparable and unambiguous parameters supporting the main indices.

In their paper, Calero-Valdez et al. [22] combined ten different empirical studies which investigated different aspects of how user diversity influences the motivation to use social media at work. Their meta-study analyzes aspects of user diversity and their correlation with eight motives for social networking sites (SNS) usage: information, importance, contact, self-presentation, autonomy, social comparison, and power and control. In their results, the individual achievement motivation correlates positively with the motives importance, power, information and self-presentation. The need for autonomy correlates with openness to new experiences and the need for social comparison with gender and neuroticism. Understanding what motivates users to use an SNS is the key to ensure the innovation capability of small and medium enterprises more affected by demographic changes and thus knowledge loss. Following these assumptions, finding a consistent model across different user groups, organizations and cultures will help in tailoring services that maximize individual usage satisfaction and organizational utility.

Finally, Gonçalves et al. [23] addressing the importance associated with e-commerce Web site accessibility performed a study on one of the most relevant Portuguese e-commerce Web sites. At an initial stage, they evaluated the chosen Web site with a Web accessibility and usability automatic tool called SortSite; they then performed a manual evaluation to verify each previously detected error and possible solutions. In the third phase, three usability specialists were used to perform a heuristic evaluation of the chosen Web site, and finally, a user test with blind people was carried out in order to fully assess the compliance with accessibility and usability guidelines and standards. The results showed that the platform had a good score regarding the automatic evaluation; however, when the heuristic and manual evaluations were performed, some accessibility and usability problems were discovered. Moreover, the user test results regarding efficiency, effectiveness and satisfaction were not positive. As a conclusion, they highlight user interaction problems and propose seven recommendations focused on enhancing accessibility and usability of not only the evaluated e-commerce Web site, but also other similar ones.

In conclusion, this special issue (in its two parts) presents some different approaches with novel data and solutions related to the improvement in the information society skills [24]. As previously stated, knowledge, in general, and data, interactions and accessibility to content in particular are primary goals in our digitalized society. For these reasons, it is necessary to empower collaboration and learning by taking advantage of human abilities to use and manipulate mobile and digital devices. The proposed methods, case studies and analysis add new ideas for data representation and access to all type of data, something that quickly must improve the Universal Access and usability of contents [25].

The Guest Editors wish to thank the Editor-in-Chief of the International Journal Universal Access in the Information Society, Professor Constantine Stephanidis, for his patience and constant support and help with the process of editing this issue. We would also like to thank all the authors for their contributions and the reviewers for their assessment of the papers. We hope that the readers of the UAIS Journal will find the papers of this special issue interesting.

The Guest Editors.

David Fonseca, Miguel Ángel Conde.

List of reviewers.

Xavier Canaleta, vice-dean in Educational Innovation at La Salle, Universitat Ramon Llull, Spain.

Manuel Contero, full professor of Engineering Graphics and CAD at Polytechnic University of Valencia, Spain. Juan Cruz, member of the Research Group of Interaction and eLearning of Salamanca University, Spain.

Jorge Dorribo, assistant professor in dean at University of Houston, Texas, USA.

Francisco José Garcia-Peñalvo, full professor and manager of Research Group in Interaction and eLearning of Universidad de Salamanca, Spain.

Alicia García, member of the Research Group of Interaction and eLearning of Salamanca University, Spain.

Ramiro Gonçalves, associate professor of Trás-osMontes e Alto Douro, Vila Real, Portugal.

Dai Griffiths, full professor of Educational Cybernetics at University of Bolton, UK.

Angel Hernández, assistant professor in Information Technologies at Polytechnic University of Madrid, Spain. 
Luis Hernández, associate professor and manager of Research Group in advanced visualization at Universidade da Coruña, Spain.

Zahid Hussain, professor and dean at Technische Universität Graz, Austria.

Faraon Llorens, full professor in Artificial Intelligence and Computation at Alicante University, Spain.

Merche Marqués, associate professor in Artificial Intelligence and Computation Sciences at Jaume I of Castellón University, Spain.

José Luís Bandeira Rodrigues Martins, assistance professor of Trás-os-Montes e Alto Douro, Vila Real, Portugal.

Vicente Matellán, associate professor of Computer Science at University of León, Spain.

Ravi Mokashi, professor and dean in the Department of Design of Indian Institute of Technology Guwahati, India.

Miroslav Minovic, assistant professor at University of Belgrade, Serbia.

Rafael Molina, associate professor in Artificial Intelligence and Computation at Alicante University, Spain.

Fernando Moreira, associate professor at Economics, Management and Informatics department of Universidade Portucalense, Portugal.

Tihomir Orehovački, assistant professor at Juraj Dobrila University of Pula, Croatia.

Salvatore Flavio Pileggi, Research fellow in the Schools of Information Technology and Electrical Engineering at the University of Queensland, Australia.

Manuel Pérez Cota, full professor at Department of Computer Sciences of University of Vigo, Spain.

Ernest Redondo, associate professor and vice-dean of Architecture at Polytechnic University of Catalonia, Spain.

Salvador Ros, associate professor and vice-dean of Technologies in the Computer Science School of the National Distance Education University (UNED), Spain. Marisa Sein-Echaluce, associate professor at Department of Applied Mathematics, Zaragoza University, Spain.

Francisco Sedano, assistant professor at Informatics Department of León University, Spain.

Teija Vainio, HCI and User Experience Design researcher at University of Tampere, Finland.

Andrea Valente, associate professor at Southern Denmark University, Denmark.

\section{References}

1. Stafford, L., Hillyer, J.D.: Information and communication technologies in personal relationships. Rev. Commun. 12(4), 290-312 (2012). doi:10.1080/15358593.2012.685951
2. Oliver, R.: The role of ICT in higher education for the $21 \mathrm{st}$ century: ICT as a change agent for education. In HE-21 Conference on the Role of ICT in Higher Education. (2002). doi:10. 1080/09687760500376439

3. Gherardi, S., Nicolini, D., Odella, F.: Toward a social understanding of how people learn in organizations: the notion of situated curriculum. Manag. Learn. (1998). doi:10.1177/1350507698293002

4. Eraut, M.: Non-formal learning and tacit knowledge in professional work. Br. J. Educ. Psychol. (2000). doi:10.1348/ 000709900158001

5. Marsick, V.J., Watkins, K.E.: Informal and incidental learning. New Dir. Adult Contin. Educ. (2001). doi:10.1002/ace.5

6. Glaser, R.: Education and thinking: the role of knowledge. Am. Psychol. 39(2), 93-104 (1984). doi:10.1037/0003-066X.39.2.93

7. Prensky, M.: Digital natives, digital immigrants part 1 . On the Horizon 9, 1-6 (2001). doi:10.1108/10748120110424816

8. van Dijk, J.A.G.M., Hacker, K.: The digital divide as a complex and dynamic phenomenon. Inf. Soc. (2003). doi:10.1080/ 01972240309487

9. Bennett, S.C., Maton, K., Kervin, L.: The "digital natives" debate: a critical review of the evidence. Br. J. Educ. Technol. 39(5), 775-786 (2008). doi:10.1111/j.1467-8535.2007.00793.x

10. Stephanidis, C.: Adaptive techniques for universal access. User Model. User Adapted Interact. (2001). doi:10.1023/A: 1011144232235

11. Bonfadelli, H.: The internet and knowledge gaps: a theoretical and empirical investigation. Eur. J. Commun. 17(1), 65-84 (2002). doi:10.1177/0267323102017001607

12. Warschauer, M.: Technology and Social Inclusion: Rethinking the Digital Divide. Technology and Social Inclusion: Rethinking the Digital Divide. (2003). doi:10.1086/428699

13. Rømen, D., Svanæs, D.: Validating WCAG versions 1.0 and 2.0 through usability testing with disabled users. Univ. Access Inf. Soc. 11(4), 375-385 (2012). doi:10.1007/s10209-011-0259-3

14. Fonseca, D., Redondo, E., Villagrasa, S.: Mixed-methods research: a new approach to evaluating the motivation and satisfaction of university students using advanced visual technologies. Univ. Access Inf. Soc. 14(3), 311-332 (2014). doi:10.1007/ s10209-014-0361-4

15. Salvador-Herranz, G., Camba, J.D., Naya, F., Contero, M.: On the integration of tangible elements with multi-touch surfaces for the collaborative creation of concept maps. In Lecture Notes in Computer Science (including subseries Lecture Notes in Artificial Intelligence and Lecture Notes in Bioinformatics), vol. 9753, pp. 177-186. 2016. doi:10.1007/978-3-319-39483-1_17

16. Orehovački, T., Babić, S. (In press.): Identifying relevance of quality dimensions that contribute to the universal Access of social web applications for collaborative writing on mobile devices: An Empirical Study. Universal Access in the Information Society, (this issue)

17. Fidalgo-Blanco, Á., Sein-Echaluce, M. L., García-Peñalvo, F. J. (In press). Ontological flip teaching: a flip teaching model based on knowledge management. Universal Access in the Information Society, (this issue)

18. Ferrándiz, J., Banawi, A., Peña, E. (In press): Evaluating the benefits of introducing "BIM" based on Revit in Construction Courses, without changing the course schedule. Universal Access in the Information Society, (this issue)

19. Cardoso, A., Moreira, F., Fonseca, D. (In press): Information technology infrastructure library and the migration to cloud computing. Universal Access in the Information Society, (this issue)

20. Krizanovic, V., Zagar, D., Grgic, K. (n.d.) No Title. Universal Access in the Information Society, (this issue)

21. Pileggi, S.F. (n.d.). Looking deeper into academic citations through network analysis: popularity, influence and impact. Universal Access in the Information Society, (this issue) 
22. Calero-Valdez, A., Brell, J., Schaar, A.K., Ziefle, M. (In press.) The diversity of why: a meta-analytical study of usage motivation in enterprise social networks. Universal Access in the Information Society, (this issue)

23. Gonçalves, R., Rocha, T., Martins, J., Branco, F., Au-YongOlivera, M. (In press) Evaluation of e-Commerce websites accessibility and usability: an e-Commerce platform analysis with the inclusion of blind users. Universal Access in the Information Society, (this issue)

24. García-Peñalvo, F.J., Hernández-García, Á., Conde, M.Á., Fidalgo-Blanco, Á., Sein-Echaluce, M.L., Alier-Forment, M.,
Iglesias-Pradas, S. (2017) Enhancing education for the knowledge society Era with learning ecosystems. In Open Source Solutions for Knowledge Management and Technological Ecosystems (pp. 1-24)

25. Fonseca, D.: User experience and access using augmented and multimedia technologies: special issue of UXeLATE (2012) Workshop and HCI International Conference (2013) special sessions. Univ. Access Inf. Soc. (2014). doi:10.1007/s10209-014$0360-5$ 